\title{
A importância da farmacogenética no tratamento do câncer de mama - uma revisão
}

\section{de literatura}

\author{
The importance of pharmacogenetics in the treatment of breast cancer - a literature review \\ La importancia de la farmacogenética en el tratamiento del cáncer de mama: revisión de la
}

literatura

Recebido: 11/11/2021 | Revisado: 19/11/2021 | Aceito: 22/11/2021 | Publicado: 24/11/2021

\author{
Caroline Cardoso Corrêa \\ ORCID: https://orcid.org/0000-0002-8936-5270 \\ Universidade Nilton Lins, Brasil \\ E-mail: karolinecorrea01@hotmail.com \\ Jéssica Vanina Ortiz \\ ORCID: https://orcid.org/0000-0001-7214-6816 \\ Universidade Nilton Lins, Brasil \\ E-mail: ortiz.jvm@gmail.com
}

\begin{abstract}
Resumo
Tendo em vista os relatos sobre o uso de informações genéticas germinativas na forma preventiva e no tratar desse tipo de carcinoma, bem como o seu potencial como padrões de marcadores genéticos análogos aos perfis de expressão obtidos a partir do tecido tumoral, permitindo uma previsão mais poderosa de quem responderá melhor a um tratamento ou regime específico. Com isso, este estudo tem como objetivo avaliar a importância da farmacogenética no tratamento do câncer de mama. Trata-se de uma revisão de literatura, onde foram utilizadas as bases de dados: MEDLINE, LILACS e Scielo, em que publicações em português e inglês foram selecionadas entre os anos de 2016 e 2021. Por meio dos resultados obtidos observou-se que a introdução da farmacogenética na oncologia tem possibilitado o desenvolvimento de uma nova geração de agentes farmacológicos capazes de serem seletivos contra células neoplásicas, possibilitando uma melhora significativa na relação risco/benefício de inúmeros tipos de câncer, em particular ao câncer de mama. Dessa forma, a função do farmacêutico torna-se essencial na Farmacogenética quando associado à prática clínica, já que é um profissional da saúde que detém de toda uma compreensão dos fenômenos que ocorrem nessa categoria, contribuindo no auxílio dos demais componentes do grupo funcional de saúde, realizando uma interpretação plausível dos resultados das análises e de sua posterior aplicabilidade.
\end{abstract}

Palavras-chave: Oncologia; Doenças mamárias; Genética.

\begin{abstract}
In view of the reports on the use of germline genetic information in preventive and treating this type of carcinoma, as well as their potential as patterns of genetic markers analogous to expression profiles obtained from tumor tissue, allowing a more powerful prediction who will respond best to a specific treatment or regimen. Thus, this study aims to assess the importance of pharmacogenetics in the treatment of breast cancer. This is a literature review, where the following databases were used: MEDLINE, LILACS and Scielo, in which publications in Portuguese and English were selected between 2016 and 2021. Through the results obtained, it was observed that the introduction of pharmacogenetics in oncology has enabled the development of a new generation of pharmacological agents capable of being selective against neoplastic cells, enabling a significant improvement in the risk/benefit ratio of numerous types of cancer, particularly breast cancer. Thus, the role of the pharmacist becomes essential in Pharmacogenetics when associated with clinical practice, as he is a health professional who has a full understanding of the phenomena that occur in this category, contributing to the assistance of other components of the functional health group, performing a plausible interpretation of the analysis results and their subsequent applicability.
\end{abstract}

Keywords: Oncology; Breast diseases; Genetics.

\section{Resumen}

A la vista de los reportes sobre el uso de información genética germinal de forma preventiva y en el tratamiento de este tipo de carcinoma, así como su potencial como patrones de marcadores genéticos análogos a los perfiles de expresión obtenidos del tejido tumoral, permitiendo una mayor poderosa predicción de quién responderá mejor a un tratamiento o régimen específico. Por tanto, este estudio tiene como objetivo evaluar la importancia de la farmacogenética en el tratamiento del cáncer de mama. Se trata de una revisión de la literatura, donde se utilizaron las siguientes bases de datos: MEDLINE, LILACS y Scielo, en las que se seleccionaron publicaciones en portugués e inglés entre 2016 y 2021. A través de los resultados obtenidos, se observó que la introducción de la farmacogenética 
en oncología ha permitido el desarrollo de una nueva generación de agentes farmacológicos capaces de ser selectivos frente a las células neoplásicas, permitiendo una mejora significativa en la relación riesgo / beneficio de numerosos tipos de cáncer, en particular el cáncer de mama. Así, el rol del farmacéutico se torna fundamental en Farmacogenética cuando se asocia a la práctica clínica, por ser un profesional de la salud que tiene un conocimiento pleno de los fenómenos que ocurren en esta categoría, contribuyendo a la asistencia de otros componentes del grupo funcional de la salud, realizar una interpretación plausible de los resultados del análisis y su posterior aplicabilidad.

Palabras clave: Oncología; Enfermedades de las mamas; Genética.

\section{Introdução}

No cenário atual do mundo globalizado a busca pela atenção e promoção à saúde vem ganhando destaque com relação ao bem-estar do indivíduo, onde o crescimento da racionalização terapêutica é considerado vantajoso devido à diversificação gênica que se tornam gradativamente necessárias para particularizar a terapêutica de pacientes que apresentem a mesma doença, com a justificativa de reduzir o comportamento adverso e ao nível de toxicidade do medicamento (Moreno, 2017).

O câncer de mama é o tumor maligno mais incidente em mulheres no mundo, incluindo os países mais desenvolvidos. Trata-se de um importante problema de saúde pública em virtude, principalmente, do seu diagnóstico tardio e, por conseguinte, alta mortalidade. Nos últimos anos, com a medicina moderna, tem-se observado um melhor prognóstico da doença em razão dos avanços cirúrgicos, medicamentosos e principalmente em decorrência do diagnóstico precoce (Falcetta, 2018).

No Brasil, o câncer de mama é também o tipo de câncer mais incidente em mulheres de todas as regiões, após o câncer de pele não melanoma. As taxas são mais elevadas nas regiões mais desenvolvidas (Sul e Sudeste) e a menor é observada na região Norte. Em 2021, estima-se que ocorrerão 66.280 casos novos da doença (INCA, 2019).

O câncer de mama é também a primeira causa de morte por câncer em mulheres no Brasil. A incidência e a mortalidade por câncer de mama tendem a crescer progressivamente a partir dos 40 anos (INCA, 2018).

A farmacogenética estuda como a variabilidade genética influencia na resposta individual ao tratamento farmacológico convencional, pois a genética pode interferir na eficácia e na toxicidade de um fármaco. Devido à grande diversidade de respostas a drogas, ou seja, o fato de o mesmo tratamento farmacológico apresentar respostas diferentes com relação a eficácia e toxicidade, faz-se necessária a aplicação da farmacogenética. Isso permite identificar o que causa essa variação nas respostas, e então obter uma terapia personalizada, baseada na individualidade genética, que resultará em um tratamento mais eficiente e seguro e com menor toxicidade (Cruz, 2018).

Mediante a isso, a farmacogenética apresenta-se como sendo uma importante ferramenta para oportunizar a seletividade da terapêutica apropriada ao paciente que se encontra em tratamento com câncer, pois devido à identificação de marcadores se é permitido o rastreio de portadores com modificações genéticas com respostas negativas a terapia aplicada (Cruz, 2018).

Nesse contexto, esse trabalho justifica-se, pois, a farmacogenética pode desempenhar um papel significativo em vários aspectos do câncer de mama, incluindo o prognóstico no momento de diagnóstico, resposta a tratamentos específicos e probabilidade de eventos adversos eventuais a tratamentos específicos. Lembrando que, ainda existe uma escassez de trabalhos com a finalidade de identificar variantes que podem prever o prognóstico e caracterizar respostas ao tratamento uma vez que o câncer de mama é diagnosticado.

Diante do exposto, a presente pesquisa tem como objetivo realizar um estudo sobre a importância da farmacogenética aplicada ao tratamento do câncer de mama, utilizando-se de artigos e pesquisas publicadas na comunidade científica. 


\section{Revisão bibliográfica}

\subsection{Farmacogenética}

\subsubsection{Princípios fundamentais e histórico}

Câncer de mama é o tipo de câncer mais comum entre as mulheres no mundo e no Brasil, depois do câncer de pele não melanoma. O câncer de mama responde, atualmente, por cerca de $28 \%$ dos casos novos de câncer em mulheres. O câncer de mama também acomete homens, porém é raro, representando menos de $1 \%$ do total de casos da doença. Relativamente raro antes dos 35 anos, acima desta idade sua incidência cresce progressivamente, especialmente após os 50 anos. Estatísticas indicam aumento da sua incidência tanto nos países desenvolvidos quanto nos em desenvolvimento. Existem vários tipos de câncer de mama. Alguns evoluem de forma rápida, outros, não. A maioria dos casos tem bom prognóstico (OMS, 2020).

Uma das estratégias do diagnóstico precoce é a educação das mulheres e dos profissionais de saúde objetivando reconhecer os sinais e sintomas, a orientação quanto ao autoexame da mama, reforçando a necessidade da realização da autopalpação. Estatísticas demostram que aproximadamente $65 \%$ das mulheres identificam o câncer casualmente e $35 \%$ por meio de autoexame mensal (INCA, 2019). A indicação do autoexame como forma de prevenção é controversa visto que não há estudo que comprove a redução da mortalidade com essa medida, quando indicada de forma periódica e metódica. No entanto, há consenso da importância do conhecimento do próprio corpo e da identificação das alterações que possam sugerir a neoplasia da mama.

Quando diagnosticada no início, o tratamento possui maior potencial curativo. No caso de doença avançada, com metástases, o tratamento tem por objetivo prolongar a sobrevida e melhorar qualidade de vida (INCA, 2019).

O tratamento pode ser dividido em:

- Tratamento local: cirurgia e radioterapia

- Tratamento sistêmico: quimioterapia, hormonioterapia, terapia biológica.

Descoberta de biomarcadores e novos agentes terapêuticos direcionados no câncer de mama, têm mobilizado grandes investimentos científicos e financeiros, principalmente por parte da indústria farmacêutica internacional. Os custos no desenvolvimento de novas drogas em oncologia superam cerca de 50 bilhões de dólares americanos anualmente (Rosenblatt, 2017). No entanto, o crescente e constante progresso dos conhecimentos desses alvos ou vias de sinalização fazem parte, dentro de uma perspectiva histórica, do passado. O futuro será resultado de estudos pré-clínicos ou clínicos desenvolvidos no presente. Nesta direção, uma série de drogas têm sido testadas e sinalizam como a doença poderá ser continuadamente controlada (Pegram et al., 2018).

A partir desse fato, no ano de 1959, o pesquisador Friedrich Vogel utilizou inicialmente a expressão farmacogenética associando-a com o aparecimento de adversidades reacionais que acometiam os indivíduos logo após o uso de certos medicamentos, possivelmente produzidos por polimorfismo gênico.

É relevante observar que mesmo que os princípios implícitos à Farmacogenética tenham sido percebidos há alguns anos, somente foram utilizados de forma terapêutica mais recentemente, sendo usados como ferramentas de avaliação e acompanhamento do paciente em termos da utilização clínica por causa do crescimento das pesquisas efetivadas no decorrer nos anos, incluindo os avanços tecnológicos combinados com a evolução gênica (Weitzel, Cavallari \& Lesko, 2017).

Na visão de Lazaridis (2017), a trajetória de saúde dos pacientes quando a doença é diagnosticada até chegar ao momento de sua melhora é semelhante a uma peripécia terapêutica, onde a busca por uma terapêutica qualificada é o alvo fundamental, devido à várias problemáticas como: insucessos terapêuticos e o aparecimento de sistemas e reações antagônicas.

Já Dong e Wiltshire (2017), afirmam que nem todos os pacientes reagem igualmente a certo tipo de medicamento, sendo dessa forma, perceptível que cada indivíduo sentir de um jeito diferente seus sintomas, devido a vários cofatores, tais 
como: condições ambientais, relação entre os medicamentos, condições fisiológicas direcionadas ao tipo de enfermidade que o paciente apresenta e, em sua maioria, o polimorfismo gênico.

Mediante a isso, a variabilidade gênica do processo enzimático contribui de maneira plausível nas características físicas do indivíduo de acordo com Rivera et al. (2021), agindo de uma forma para medicamentos ativos e de outra forma para inativos, dependendo da atividade terapêutica e principalmente do grau de metabolização dos pacientes. Sob essas características torna-se importante compreender as diferenças existentes na medicina clássica e a na medicina personalizada para que se entenda o propósito da aplicabilidade da farmacogenética em meios aos diversos tratamentos carcinogênese.

\subsubsection{Diferença entre medicina clássica e medicina personalizada}

Segundo denota Lazaridis (2017), a atividade da medicina tradicional está fundamentada na aplicabilidade de regras de terapias por patologia, incluindo algumas advertências sobre quais precauções tomar. Nesse caso, essas preposições foram desenvolvidas, sendo que estes protocolos são desenvolvidos a partir das atividades e de testes clínicos representando os diversos genótipos escalados em sua totalidade amostral. Por volta do século XX aparece um novo modelo metodológico baseando-se na farmacogenômica e nas orientações relevantes para cada fármaco estudado. A partir de então, surge a medicina personalizada.

O surgimento de patologias mais complexas, como as do tipo carcinogênese múltipla, e o processo evolutivo de formulação de novos medicamentos, fazem com que haja um crescimento na busca por respostas positivas para área da farmacoterapia, tornando esta questão um desafio para os servidores atuantes na prática. Dessa maneira, as inovações farmacêuticas são elaboradas com o objetivo de alcançar aspectos moleculares com alta especificidade, devido ao fato de serem puramente ativos, entretanto acarretam o desencadeamento de reações antagônicas e até mesmo que podem levar a morte, por isso se faz necessário escolher o medicamento adequado para o paciente tratado (Urenã \& Resenkranz, 2018).

Mediante a isso, a medicina personalizada assume a função de inovar por intermédio do desenvolvimento marcadores biológicos dentro da farmacogenética, a fim de melhorar a atuação medicinal e consequentemente no bem-estar dos pacientes. Entretanto, é preciso que as pesquisas tecno-científicas passem a serem aplicadas em uma dimensão realista para a população amostral, ampliando a sua aplicação, por meio de métodos de efetivação em diversos centros de saúde (Carpenter et al., 2016).

\subsection{Aplicabilidade da farmacogenética na prática clínica}

\subsubsection{Otimização da terapêutica}

Estima-se que nos Estados Unidos cerca de 75-96\% das terapêuticas prescritas não são efetivas nomeadamente as que envolvem medicamentos que geram maior receita, podendo dar origem a consequências bastante negativas tanto para os doentes como para a economia do país (Dong \& Wiltshire, 2017).

A Sociedade Americana de Farmacêuticos do Sistema de Saúde - ASHP (2015), afirma que os testes farmacogenéticos podem melhorar todos os aspectos relacionados com a terapêutica se aplicados continuadamente em todos os serviços do sistema de saúde, apontando como grandes vantagens desta prática a diminuição dos custos associados ao tratamento, o aumento da adesão à terapêutica, uma melhor seleção da medicação, diminuição do período de tratamento e ainda o aumento da segurança do doente.

O desenvolvimento do medicamento certo para um grupo específico de doentes fenotipicamente idênticos aumentaria o número de prescrições por parte dos médicos, contribuindo para o retorno de todo investimento da indústria (Mirsadaghi \& Larijani, 2017). 


\subsubsection{Exemplos de aplicação da Farmacogenética no tratamento de câncer}

O desenvolvimento das células cancerígenas ocorre quando as células com vida perdem o controle do sistema de replicação celular, tornando-se incapazes de eliminar ou minimizar as fases decorrentes do sistema celular em termos de mutações gênicas. Nesse quesito as mutações germinativas terão implicações na forma como o organismo corresponde à presença de certo medicamento (farmacocinética), normalmente em nível metabólito (Kranzler et al., 2017).

Na concepção do pesquisador Lazaridis (2017), uma possível resolução para elevar a eficiência dos fármacos e reduzir o nível de toxidez das terapêuticas quimioterápicas são exatamente os testes farmacogenéticos relacionados a farmacocinética.

Desse modo, quando se avalia os diversos tipos cancro, verifica-se que as mulheres são as portadoras do cancro de mama, que por sua vez leva a morte, sendo que já é estimado que surjam 6.000 novos casos por ano e que ocorram cerca de 1.500 mortes. De acordo com a Direção Geral da Saúde (DGS) sobre o tratamento do cancro da mama metastático, doentes que sejam tipificados como HER-2 (Human Epidermal growth factor Receptor-type 2) positivo devem iniciar terapêticas que incluam um agente anti-HER-2, como é o caso do trastuzumab (Norma da Direção-Geral da Saúde, 2012), sendo que o gene HER-2 encontra-se no cromossoma 17 e a sua aplicação é observada em cerca de 15-20\% dos casos de cancro, estando relacionada ao sucesso das terapêuticas anti-HER-2 (Kim et al., 2017).

Em razão do uso específico do trastuzumab está sujeito a justaposição dos genes HER-2, é essencial a efetuação de análises farmacogenéticas antes de iniciar o tratamento com trastuzumab, com a finalidade de quantificar a expressão do gene e proporcionar ao doente o melhor tratamento possível em termos de eficiência e proteção. A superexpressão de receptores do fator de crescimento epidérmico humano tipo 2 (HER-2) é observada em torno de $25 \%$ a $30 \%$ dos casos de câncer de mama. Nessa superexpressão, há proteínas transmembranas extras funcionando como receptores do fator de crescimento, induzindo à dimerização e à consequente determinação para uma divisão e multiplicação celular acelerada. Os tumores são considerados HER-2 positivos quando apresentam resultados de grau 3+ ao exame de imunohistoquímica (ICH), comprovados pela hibridização in situ por fluorescência (FISH) demonstrando amplificação do gene HER-2. Podem ocorrer ainda tumores que não apresentam superexpressão do gene HER-2, mas que apresentam amplificação (Kim et al., 2017).

Nesse pensamento, o trastuzumab está submetido ao desempenho de reações antagônicas, tais como: toxicidade cardíaca, reações associadas à perfusão, reações pulmonares ou ainda toxicidade hematológica. Somente os pacientes que estão subordinados ao HER-2 se beneficiam do tratamento com trastuzumab, na medida em que este apenas irá desempenhar a sua utilidade terapêutica nesta preposição. Os protocolos para a constatação da aplicação do HER-2, ou na amplificação do gene HER-2, fundamentam-se em técnicas de imunohistoquímica de fragmentos de biópsia tumoral fixada ou pelo uso da técnica de hibridação in situ de fluorescência ou hibridação in situ cromogênica, reciprocamente.

Outros tipos de cancros podem ser abordados como instrumentos farmacogenéticos, tal como, o colorretal mestático. Nesse caso, é necessário o desenvolvimento de procedimentos e análises dos proponentes da farmacogenética em pessoas detectadas com cancro colorretal metastático, haja visto que acabam por possibilitar a previsão de possíveis resultados positivos a terapêutica dos fármacos quimioterápicos anti-EGFR em conformidade com a ausência ou a presença de mutações no gene KRAS.

\subsubsection{Estratégias para efetivação da farmacogenética tratamento de câncer}

Os tratamentos sistêmicos para câncer de mama são divididos em: intervenções hormonais, quimioterapia e novos agentes. Atividade antitumoral ou segurança de agentes específicos podem depender não só na dose e horário do medicamento, mas também nos alvos funcionais, metabolização de drogas enzimas e transportadores (Urenã \& Resenkranz, 2018). 


\subsection{Terapia hormonal}

Em mais de 50\% da mama primária os cânceres expressam o receptor de estrogênio (ER) e/ou receptor de progesterona (PgR). Praticamente em todas as mulheres com doença de receptor de hormônio positivo irá ser oferecido alguma forma de hormônio interversor para tratar o câncer (Moreno, 2017).

Dessa forma, a maioria das mulheres com câncer de mama precoce vão provavelmente receber tamoxifeno adjuvante por 5 anos, enquanto para as mulheres na pós-menopausa podem ser oferecidos inibidores de aromatase (enzima do grupo do citocromo P450 que catalisa a aromatização dos androgénios em estrogénios) e mulheres na pé-menopausa podem sofrer supressão com ou sem tamoxifeno. De todo o modo, o Tamoxifeno também foi aprovado para reduzir a incidência de um novo câncer de mama em mulheres em com alto risco a doença (Moreno, 2017).

\subsubsection{Tamoxifeno}

Entre os tratamentos para câncer de mama, existe o feito com o tamoxifeno, um medicamento original não esteróide com atividade agonista e antagonista mista. Essa droga exerce seus efeitos ligando-se aos receptores de estrogênio e modulando a transcrição induzida por estrogênio. É metabolizada extensivamente por meio de o sistema do citocromo P450 ao seu metabólito $\mathrm{N}$-desmetilado primário, mas também para uma série de metabólitos antiestrogênicos potentes, incluindo 4hidroxi-tamoxifeno e 4-hidroxi-Ndesmetil-tamoxifeno (endoxifeno) (Moreno, 2017; Mandel, 2019).

O que se pode afirmar por intermédio da literatura é que o tamoxifeno reduz o risco de recorrência do câncer de mama em receptores hormonais positivos em 50\%. Entretanto, enquanto a presença de ER e/ou PgR é fundamental para a seleção de pacientes que podem se beneficiar de tamoxifeno, algumas mulheres com receptor de hormônio positivo irão recorrer, apesar do tratamento, devido à resistência de novo ou adquirida (Scott, 2017).

Uma visão geral desses estudos sugere que o tamoxifeno reduz o risco de um novo câncer de mama ER positivo em 38\% (95\% intervalo de confiança (IC) 28-46; Po0.0001). Apesar do grande número de mulheres inscritas nos estudos de tamoxifeno como agente preventivo, uma melhora na mortalidade não foi demonstrada, e é improvável que tais dados estarão disponíveis. Além disso, o tamoxifeno foi associado a efeitos adversos graves raros, incluindo câncer uterino e doença tromboembólica (Marquez, Balcázar \& Aristizábal 2016).

Dado o possível grau de toxicidade e a eficácia incompleta da droga, existem ferramentas que podem ajudar a identificar mulheres com maior probabilidade de se beneficiar e/ou menos propensos a sofrer efeitos adversos eventos são necessários. O tamoxifeno é metabolizado no fígado por várias enzimas do citocromo P450. Dados recentes sugerem que outros metabólitos podem ser tão importantes quanto 4-hidroxi-tamoxifeno na atividade do tamoxifeno e pode ser influenciado por efeitos farmacogenéticos (Marquez, Balcázar \& Aristizábal 2016).

\subsubsection{Inibidores de aromatase}

De acordo com Silva, Castro e Figueiredo (2020), os inibidores da aromatase bloqueiam a conversão de andrógenos em estrógenos, exercendo atividade antitumoral pela depleção dos estrogênios circulantes. Diversos estudos demonstraram superioridade de inibidores da aromatase sobre o tamoxifeno como tratamento de primeira linha para o câncer de mama metastático.

O uso de 5 anos de letrozol, após 5 anos de tamoxifeno melhora ainda mais a sobrevida livre de doença. Assim, no uso de aromatase, os inibidores provavelmente aumentarão. No entanto, como acontece com o tamoxifeno, nem todas as mulheres com receptor de hormônio positivo irão se beneficiar de inibidores de aromatase. Efeitos adversos dos inibidores da aromatase, que resultam da redução nos estrogênios circulantes, podem incluir perda óssea, artralgias/mylagias e calor flashes (Moreno, 2017). 
Assim, a redução da densidade da mama em tratamento com tamoxifeno ou inibidor de aromatase irá se correlacionar diretamente com o risco reduzido de desenvolver um novo câncer ou a uma recorrência não conhecida. Finalmente, o polimorfismo em enzimas que metabolizam.

\subsubsection{Quimioterapia}

Vários agentes e combinações de regimes de quimioterapia são eficazes para o tratamento de câncer de mama. Na doença metastática, o objetivo da terapia é melhorar o tempo de progressão, qualidade de vida e possivelmente sobrevida global (Rivera et al, 2021).

Na visão de Bray et al. (2018), a cura é um objetivo atraente, mas raramente é alcançado neste cenário. Em contraste, em a configuração adjuvante, o objetivo final é melhorar a sobrevida geral e/ou livre de doença. A dose ideal e cronograma de quimioterapia são geralmente determinados na fase I dos ensaios clínicos, geralmente no cenário metastático, quando as toxicidades limitantes da dose são avaliadas e uma dose máxima tolerada está determinado. Logo, no câncer de mama adjuvante, a quimioterapia combinada tem sido o padrão de tratamento para muitas mulheres durante décadas. Combinações de ciclofosfamida e/ou à base de antraciclina terapia geralmente é administrada.

\subsubsection{Metorexato}

O metotrexato de agente único é MTX é um antimetabólito e uma droga antifolato usada no tratamento do câncer e doenças autoimunes. Metotrexato inibe a dihidrofolato redutase, resultando na depleção parcial da redução de folatos (Carrondo, 2016).

O regime é bastante bom tolerado pela maioria das mulheres, mas uma pequena parte pode sofrer mielossupressão aguda. Os pesquisadores levantaram a hipótese que polimorfismos na metilenotetrahidrofolato redutase (MTHFR) gene pode resultar em toxicidade diferencial para CMF (Cruz, 2018; Rivera, 2021).

\section{Objetivos}

\subsection{Objetivo geral}

- Avaliar a importância da farmacogenética no tratamento do câncer de mama.

\subsection{Objetivos específicos}

- Descrever o processo histórico da farmacogenética e atuação no tratamento do câncer de mama;

- Comparar tratamento clássico com a inclusão da farmacogenética;

- Identificar a aplicabilidade do uso da farmacogenética no tratamento de câncer de mama.

\section{Metodologia}

Trata-se de uma pesquisa de revisão de literatura ou bibliográfica, que identificou artigos publicados entre 2016 a 2021.

A coleta de dados foi realizada por meio de produções publicadas por meio das seguintes fontes de dados: MEDLINE (Medical Literature Analysis and Retrieval System Online), LILACS (Literatura Latino-Americana em Ciências da Saúde) e SCIELO (Scientific Eletronic Library Online), utilizando as seguintes palavras-chave: Farmacogenética, Farmacogenômica, câncer, pharmacogenetics, pharmacogenomics, câncer, Mama e Oncologia. 
No total foram coletados 40 artigos, se fazendo necessário realizar uma etapa de leitura, refino e filtragem a fim de se obter por etapa de inclusão e exclusão somente os ideais para a confecção dessa pesquisa. Na etapa de inclusão foram integradas pesquisas, artigos originais e revisões divulgadas durante os cinco anos em periódicos nacionais e internacionais, apresentando dados com informações pertinentes a esse tema abordado. Na etapa de exclusão foram retirados os artigos divulgados em anos anteriores, com duplicidade, e que não se encaixaram no objetivo da pesquisa. Assim, a amostra final foi constituída por 10 artigos. Após os artigos serem analisados e avaliados, foi utilizado como instrumento de coleta de dados uma tabela do tipo integrativa, onde estão presentes as seguintes informações: Título; Autores; Ano (País); Detalhamento do estudo e desfechos.

\section{Resultados e Discussão}

Dos 40 artigos, 28 foram selecionados e será apresentada a tabela integrativa (Quadro 1) dos resultados referentes aos estudos de literaturas sobre o tema farmacogenética no tratamento do câncer de mama, para a construção do pensamento filosófico sobre a relevância da aplicabilidade da farmacogenética ou farmacogenoma na oncologia.

Quadro 1. Quadro integrativo da pesquisa - Farmacogenética.

\begin{tabular}{|c|c|c|c|}
\hline Autor (es) & Ano/País & Tipo de estudo & Desfechos \\
\hline Santos et al. & 2016/Brasil & $\begin{array}{l}\text { Revisão } \\
\text { sistemática }\end{array}$ & $\begin{array}{l}\text { Os autores analisados enfatizaram a importância da aplicação da farmacogenética na oncologia, } \\
\text { estabelecendo fatores como: } \\
\text { - Segurança; } \\
\text { - Adesão ao tratamento; } \\
\text { - Sequelas resultantes de falhas terapêuticas; } \\
\text { - Medicação; } \\
\text { - Intoxicação; } \\
\text { - Internações de alto custo. }\end{array}$ \\
\hline $\begin{array}{l}\text { Pinho, Sitmik } \\
\& \text { Mangueira. }\end{array}$ & 2017/ Brasil & $\begin{array}{l}\text { Pesquisa de } \\
\text { revisão de } \\
\text { literatura }\end{array}$ & $\begin{array}{l}\text { - Testes genéticos; } \\
\text { - A detecção de HER-2 por técnica de imunohistoquímica; } \\
\text { - Tratamento de câncer de mama com trastuzumabe; } \\
\text { Exames que podem indicar que alguns medicamentos efetivos (por exemplo, a presença da } \\
\text { translocação BCR/ABL ou PML/RARA, indicando tratamentos específicos para } \\
\text { leucemias, ou a presença da mutação V600E, indicando tratamento específico em } \\
\text { melanomas). }\end{array}$ \\
\hline $\begin{array}{l}\text { Drögemöller } \\
\quad \text { et al. }\end{array}$ & $\begin{array}{l}2017 / \\
\text { Estados } \\
\text { Unidos. }\end{array}$ & $\begin{array}{l}\text { Pesquisa } \\
\text { exploratória com } \\
\text { abordagem } \\
\text { qualitativa }\end{array}$ & - Variação do código proteico no SLC16A5 e os efeitos ototóxicos induzidos pela cisplatina. \\
\hline Moreno et al. & 2017/ Brasil & $\begin{array}{l}\text { Pesquisa } \\
\text { exploratória com } \\
\text { abordagem } \\
\text { qualitativa } \\
\end{array}$ & $\begin{array}{l}\text { - Os estudos têm demonstrado que durante cinco anos de tratamento, o tamoxifeno tem } \\
\text { reduzido as taxas em } 41 \% \text { dos casos e de morte por câncer de mama, em até } 34 \% \text { das } \\
\text { pacientes. }\end{array}$ \\
\hline $\begin{array}{l}\text { Lopez-cortes } \\
\quad \text { et al. }\end{array}$ & 2017/ Chile & $\begin{array}{l}\text { Pesquisa de } \\
\text { revisão de } \\
\text { literatura }\end{array}$ & $\begin{array}{l}\text { - Comparação étnica de perfis farmacogenômicos, expressão gênica e regulação; o impacto do } \\
\text { polimorfismo no fenótipo; perfis metabólicos de pacientes com um determinado } \\
\text { medicamento; e fatores ambientais relevantes que influenciam a resposta ao medicamento. }\end{array}$ \\
\hline Cruz et al. & 2018/ Brasil. & $\begin{array}{l}\text { Estudo } \\
\text { qualitativo }\end{array}$ & $\begin{array}{l}\text { - O gene que codifica o CYP2D6 é altamente polimórfico e as variantes mostram uma } \\
\text { grande diversidade entre os diferentes genótipos e populações }\end{array}$ \\
\hline Kranzler et al. & $\begin{array}{l}2017 / \\
\text { Estados } \\
\text { Unidos }\end{array}$ & $\begin{array}{l}\text { Pesquisa } \\
\text { qualitativa }\end{array}$ & - O desenvolvimento de biomarcadores farmacogenéticos em oncologia. \\
\hline Silva et al. & 2020/ Brasil. & $\begin{array}{l}\text { Trata-se de uma } \\
\text { revisão de } \\
\text { literatura. }\end{array}$ & - Os mecanismos epigenéticos relacionados ao câncer de mama. \\
\hline $\begin{array}{l}\text { Carpenter et } \\
\text { al. }\end{array}$ & $\begin{array}{l}\text { 2016/ } \\
\text { Estados } \\
\text { Unidos. }\end{array}$ & $\begin{array}{l}\text { Pesquisa } \\
\text { quantitativa }\end{array}$ & $\begin{array}{l}\text { - O objetivo do estudo foi avaliar o escopo potencial da implementação de testes } \\
\text { farmacogenéticos de múltiplas drogas em um sistema de saúde de grande rede de segurança. }\end{array}$ \\
\hline $\begin{array}{l}\text { Iriart \& } \\
\text { Caprara }\end{array}$ & 2019/ Brasil & $\begin{array}{l}\text { Trata-se de uma } \\
\text { revisão de } \\
\text { literatura. }\end{array}$ & $\begin{array}{l}\text { - A revisão aponta que muitas das promessas da medicina de precisão ainda não se } \\
\text { concretizaram. Se por um lado houve enorme avanço no conhecimento sobre os mecanismos } \\
\text { moleculares das patologias e o desenvolvimento de medicamentos que impactaram } \\
\text { significativamente o tratamento de alguns tipos de câncer, até o momento não há evidências } \\
\text { de que este padrão se reproduzirá em outras doenças complexas. }\end{array}$ \\
\hline
\end{tabular}

Fonte: Elaborado pelos autores (2021). 
Com a evolução tecnológica percebe-se que os testes genéticos estão a cada dia mais acessíveis devido a razão dos preços estão cada vez mais reduzindo, sendo possível a obtenção de maiores informações e conhecimento sobre o perfil genômico, atuando como uma ferramenta essencial para os servidores da área saúde.

As principais dificuldades encontradas pelas organizações, de acordo com pesquisa na investigação farmacogenômica em ensaios clínicos foram: considerações estatísticas (tamanho da amostra, a heterogeneidade genética), considerações logísticas (aprovação do Comitê de Ética, dificuldade de recrutamento), considerações científicas (disponibilidade de genes candidatos), atraso no calendário e o gasto da parte técnica. Deve-se ressaltar que esta aplicação terá um impacto revolucionário na atividade clínica, e acarretará na redução de mortalidade relacionada aos fármacos, a diminuição de gastos sanitários e maior conscientização do uso racional de medicamentos (Lazaridis, 2017).

Nesse pensamento, com o avanço da farmacogenômica aplicada a oncologia e com o desempenho de estudos farmacogenômicos oportunizará o desenvolvimento de novas classes de fármacos, diagnóstico e prognóstico molecular das doenças, terapia celular e gênica, a individualização de tratamentos, a progressão de uma medicina otimizada, a comprovação de novos genes regulados por fármacos, onde ocorrerá um grande avanço terapêutico na prática clínica e ainda ganhos econômicos.

O que se pode concluir é que a farmacogenética/genômica apresenta possibilidades bastante promissoras para o aprimoramento da terapia do câncer, bem como a redução da toxicidade e elevação da eficácia, através da otimização da escolha do tratamento mais adequado, individualização de doses e descoberta de novos alvos. Como visto no decorrer dessa pesquisa, em diversos casos essa estratégia não se apresenta mais como uma promessa antes sim já influencia decisões clínicas.

Cumprindo o segundo objetivo específico desse trabalho, no quesito de demonstrar uma possível abordagem esquemática e diagnóstica da terapêutica do câncer segundo fatores farmacogenéticos, verificou-se que existem parâmetros que servem como base para futuras observações, incluindo etapas em que o desempenho genômico do tumor seria determinado, atuando para projeções prognósticas mais precisas e adoção de medidas terapêuticas eficientes e menos tóxicas.

Dessa forma, fármacos adequados para um perfil genômico tumoral específico seriam selecionados dentre um amplo arsenal de agentes terapêuticos de alta especificidade. Na etapa seguinte seria avaliada a adequação dessas escolhas com base nos dados farmacogenéticos dos pacientes (Figura 1). 
Figura 1. Abordagem diagnóstica e terapêutica do câncer segundo fatores farmacogenéticos.

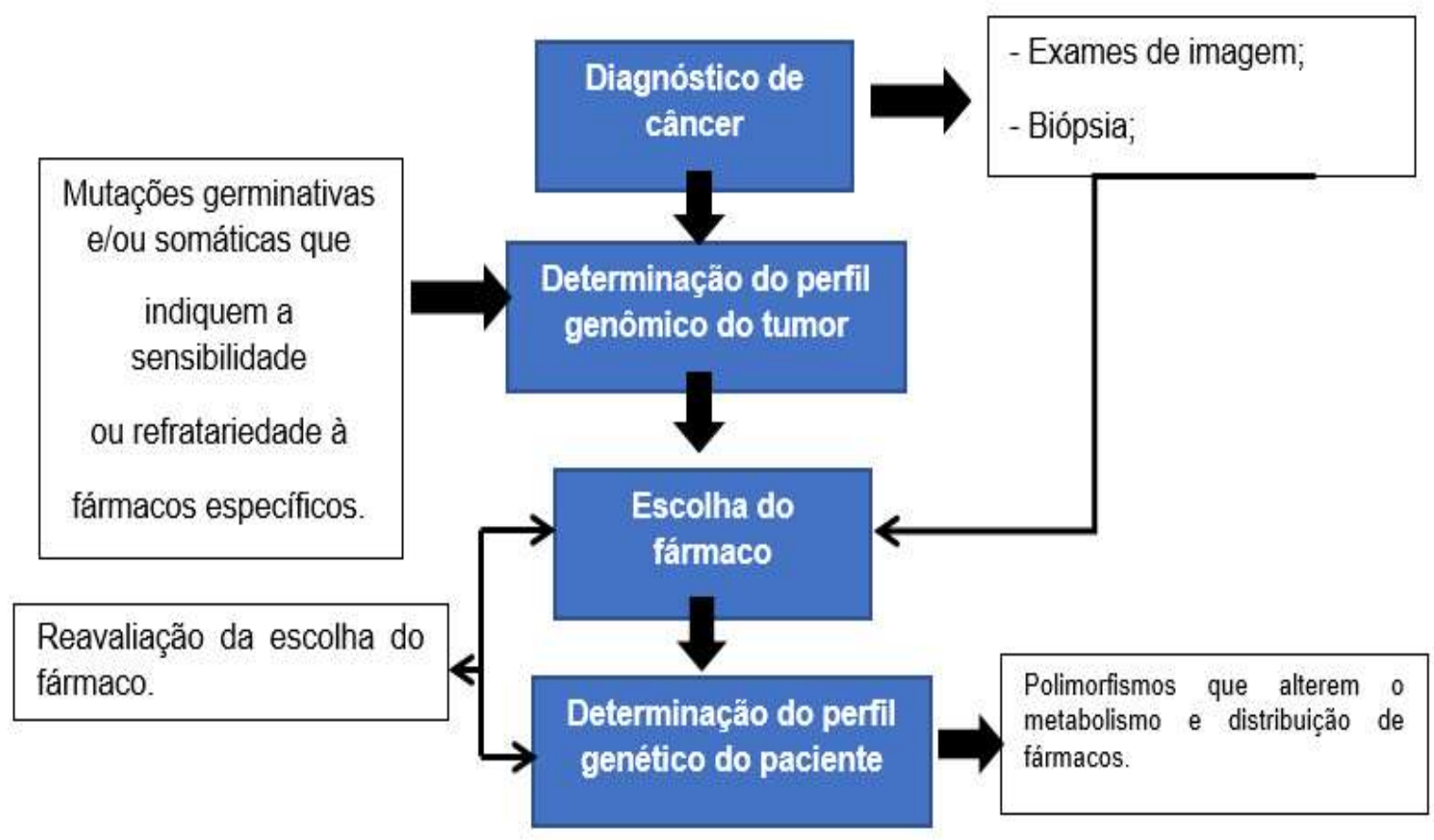

Fonte: Autores (2021).

O que se pode observar é que na individualização da terapia com base em diversidades gênicas que alterem qualitativa ou quantitativamente a função de genes específicos, se torna um pouco mais fácil quando essas variações são germinativas (polimorfismo genético). Quando a variação decorre de transformações genéticas a dificuldade aumenta haja vista que a análise genômica depende da obtenção de amostras de tecidos tumorais. No caso das doenças linfo/mielo proliferativas, o ganho de tecidos é mais fácil já que amostras podem ser coletadas do sangue periférico. No caso dos tumores sólidos, a obtenção depende da efetuação de biópsia ou cirurgia.

Nesse caso, uma saída plausível para essa limitação é a análise genômica global dos diferentes tumores sólidos, a fim de identificar as alterações somáticas a serem alvejadas através, certamente, do uso concomitante de vários agentes alvoseletivos. Para atingir esse estágio serão necessários estudos de genômica funcional que contribuam para o entendimento da biologia tumoral e determinação da relevância das alterações genéticas para a progressão da doença ou resposta à terapia.

Atualmente, uma fração muito pequena dos investimentos da indústria farmacêutica é destinada aos estudos e experimentos que viabilizem a individualização da terapêutica. Muitos artigos têm sido publicados identificando a influência de variações genéticas sobre fármacos específicos. Muitas dessas associações não contam com evidências que deixem clara a relevância clínica dessas informações. Isso exigirá além da análise genômica e estudos funcionais, estudos clínicos que incluam um número suficiente de pacientes sendo acompanhados por períodos mais prolongados com o intuito se obter dados mais esclarecedores.

Na verdade, percebe-se uma evolução da farmacogenética de forma a esclarecer com precisão os diversos fatores genéticos que possam influenciar a resposta à um fármaco específico, sendo possível imaginar que num futuro próximo, a progressão da tecnologia genômica leve ao desenvolvimento de kits que permitam a análise de todos os genes relevantes para resposta à um fármaco. Produtos com essa característica já vêm sendo apresentados pela indústria farmacêutica e de biotecnologia. Entretanto, a avaliação dos benefícios que eles possam trazer para a terapia farmacológica ainda depende de estudos mais detalhados e do uso em larga escala. 
Nessa perspectiva, uma das responsabilidades do profissional da saúde (Farmacêutico) é a efetivação do modelo de atividades prestadas ao paciente, tais como: a realização de testes, análises e compreensão dos procedimentos genéticos e assim, auxiliar na decisão das escolhas dos fármacos apropriados para sua utilização, lembrando que a os efeitos farmacogenéticos são essenciais e acabam influenciando na diversidade genética do indivíduo.

Assim, verifica-se que o ramo da Farmacogenética encontra-se na atualidade em alta complexidade, gerando custos elevados para os indivíduos que necessitam de cuidados específicos para cada tipo de patologias. Dessa maneira, de responder aos desafios da farmacogenética e assumir a responsabilidade de que os testes genéticos apenas serão aplicados quando estritamente necessários, com o objetivo de aperfeiçoar a terapêutica.

Logo, é essencial um estudo mais aprofundado e uma maior compressão das características que abordam a temática da farmacogenética associada ao tratamento de carcinomas, havendo uma forte ligação entre cada proponente empregado na saúde, tais como: médicos, enfermeiros, investigadores, e tecnologias devido ao fato de que quanto mais forte for essa relação mais benefícios se obtêm com o medicamento utilizado.

\section{Conclusão}

Por meio desta pesquisa pode-se aferir que a farmacogenética averigua a identificação das diversificações individuais que interferem no metabolismo ou no sistema de atividade dos medicamentos, comprometendo sua eficácia ou segurança. Desse modo, a contribuição terapêutica da farmacogenética é fornecer subsídios para a efetivação da medicina personalizada, fundamentada nas propriedades gênicas de cada indivíduo.

Observou-se nos artigos pesquisados que a farmacogenética se apresenta importante e essencial para a aquisição de uma farmacoterapia mais eficiente, proporcionando um tratamento eficaz, com menor toxicidade, aumentando a sobrevida e proporcionando um bem-estar para todos os indivíduos.

Assim sendo, a função do farmacêutico é primordial e essencial na farmacogenética, possibilitando a redução das adversidades durante as etapas de evolução de novos fármacos e o crescimento de experimentos molecular predestinadas a certos grupos de pacientes. Por fim, sugere-se que sejam feitos estudos genéticos que afetam a farmacocinética do tamoxifeno que podem ter influências adicionais sobre os desfechos de câncer de mama, e também devem ser considerados em estudos farmacogenômicos.

\section{Referências}

American Society of Health-System Pharmacists. (2015). ASHP statement on the pharmacist's role in clinical pharmacogenomics. Am J Health-Syst Pharm, $72,579-588$.

Bray, F, Ferlay, J., Soerjomataram, I., Siegel, R. L., Torre, L. A. \& Jemal. (2018). Global Cancer Statistics 2018: GLOBOCAN Estimates of Incidence and Mortality Worldwide for 36 Cancers in 185 Countries. Journal for Clinicians, 68(6), 394 - 424.

Carpenter, J. S., Rosenman, M. B., Knisely, M. R., Decker, B. S., Levy, K. D. \& Flockhart, D. A. (2016). Pharmacogenomically actionable medications in a safety net health care system. SAGE Open Medicine, 4, 1 - 8.

Carrondo, A. P. (2016). Monitorização terapêutica de fármacos. Revista Ordem Dos Farmacêuticos, 95, 1-2.

Cruz, G. C. (2018). Impacto do polimorfismo CYP2D6*4 em pacientes com câncer de mama em uso do tamoxifeno. Monografia (Graduação) - Universidade Federal do Rio Grande do Norte.

Dong, O. M. \& Wiltshire, T. (2017). Advancing precision medicine in healthcare: addressing implementation challenges to increase pharmacogenetic testing in the clinical setting. Physiological Genomics, 49(7), 346-354.

Drögemöller, B. I., Monzon, J. G., Bhavsar, A. P., Borrie, A. E., Brooks, B., Wright, G. E. B., Liu, G., Renouf, D. J., Kollmannsberger, C. K. \& Bedard, P. L. Association Between SLC16A5 Genetic Variation and Cisplatin-Induced Ototoxic effects in adult patients with testicular câncer. Jama Oncology, 3(11), 15581562. 10.1001/jamaoncol.2017.0502

Falcetta, F. S., Träsel, H. D. A. V., Almeida, F. K., Falcetta, M. R. R., Falavigna, M. \& Rosa, D. D. (2018). Effects of physical exercise after treatment of early breast cancer: systematic review and meta-analysis. Breast Cancer Res Treat, 170(3):455-76. 
Iriart, J. A. B. \& Caprara, (2011). A. Novos objetos e novos desafios para a antropologia da saúde na contemporaneidade. Physis (Rio J.), 21, $1253-1268$.

Instituto Nacional de Câncer José Alencar Gomes da Silva. (2018). Incidência, mortalidade e morbidade hospitalar por câncer em crianças, adolescentes e adultos jovens no Brasil: informações dos registros de câncer e do sistema de mortalidade. Rio de Janeiro.

Instituto Nacional de Câncer José Alencar Gomes da Silva. (2019). Estimativa 2020: incidência do Câncer no Brasil. Rio de Janeiro: INCA.

Kim, S., Yun, Y. M., Chae, H. J., Cho, H. I. M., Kim, I. S. \& Chun, S. (2017). Clinical Pharmacogenetic Testing and Application: Laboratory Medicine Clinical A aplicação da Farmacogenética em contexto de farmácia hospitalar Practice Guidelines. Annals of Laboratory Medicine, $37(2)$, 180.

Kranzler, H. R, Smith, R. V., Sshnoll, R., Moustafa, A. \& Greenstreet-Akman, E. (2017). Precision medicine and pharmacogenetics: What does oncology have that addiction medicine does not? Addiction, 112(12), 2086-2094.

Lazaridis, K. N. (2017). Improving Therapeutic Odyssey: PreemptivePharmacogenomics Utility in Patient Care. Clinical Pharmacology and Therapeutics, $101(1), 39-41$.

Lopez-Cortes, A., Guerrero, S. R., Alvarado, A. T. \& Quino, L. A. (2017). State of art of cancer pharmacogenomics in Latin American populations. International Journal of Molecular Sciences, 18(6), 1-22.

Mandel, M. N. (2019). Riesgo aumentado de cáncer de mama, ovárico y contralateral para portadoras de mutación BRCA1 y BRCA2. Actualización en la Práctica Ambulatoria, 22(3), 1-2.

Márquez, Y. V. A., Balcázar, I. B. \& Aristizábal, F. A. (2016). Tratamiento de cáncer de seno y farmacogenética. Revista Colombiana de Biotecnologia, 18(1), $121-134$.

Mirsadeghi, S. \& Larijani, B. (2017). Personalized medicine: Pharmacogeno mics and drug development. Acta Medica Iranica, 55(3), 150-165.

Moreno, L. S. (2017). O uso de tamoxifeno em pacientes com neoplasia mamária. UNILAGO, 1(1). http://revistas.unilago.edu.br/index.php/revistamedicina/article/view/15

Organização Mundial da Saúde (2021). Câncer de mama: sintomas, tratamentos, causas e prevenção. https://antigo.saude.gov.br/saude-de-a-z/cancer-demama\#: :text=Relativamente $\% 20$ raro\%20antes $\% 20$ dos $\% 2035$,forma $\% 20$ r\%C3\%A1 pida\%2C\%20outros\%2C\%20n\%C3\%A3o.

Pegram, M. D., Pivot, X., Cortes, J., Curigliano, G., Yoon, Y., Lim, J., Song, S. \& Hong E. (2019). Abstract P6-17-09: Event-free survival by ADCC status from a follow-up study comparing SB3 (trastuzumab biosimilar) with reference trastuzumab for HER2 positive breast câncer in neoadjuvant setting. Proceeding of the 2018 San antonio Breast Cancer Symposium, 79(4). 10.1158/1538-7445.SABS18-P6-17-09

Pinho, J. R., Sitmik, R. \& Mangueira, C. L. (2014). Personalized medicine and the clinical laboratoru. Eistein 12(3), $366-373$.

Rivera, J. G. B., Silva, K. R. P. da, Pantoja, B. M., Miranda, M. A., Silva, M. M. P. da \& Oliveira, Oliveira, A. E. M. de. (2021). Estudo do perfil farmacogenético das pacientes com Câncer de Mama na região Amazônica do Brazil. Brazilian Journal of Health Review, 4(3), $11723-11734$.

Rosenblatt, M. (2017). The Large Pharmaceutical Company Perspective. New England Journal of Medicine, 376(1), 52-60

Scott, S. A. (2017). Personalizing medicine with clinical pharmacogenetics. Genetics in Medicine, 13(12), 987-995.

Silva, G. A., Castro, N. S. \& Figueiredo, R. O. (2020). Mecanismos epigenéticos e a ação da expressão da proteína BRCA na carcinogênese mamária. Brazilian Journal of Development, 6(10), 82596-82613.

Urenã, A. M. \& Resenkranz, B. M. (2018). Generalidades de cáncer de mama para médico general. Medicina Legal de Costa Rica, 35(1), 44-51.

Weitzel, K. W., Cavallari, L. H. \& Lesko, J. (2017). Preemptive Panel-Based Pharmacogenetic Testing: The Time is Now. Pharmaceutical Research, 34(8), $1551-1555$. 